\title{
MicroRNA regulate immune pathways in T-cells in multiple sclerosis (MS)
}

\author{
Margareta Jernås ${ }^{1 *}$, Clas Malmeström², Markus Axelsson², Intawat Nookaew ${ }^{5}$, Hans Wadenvik $^{3}$, Jan Lycke ${ }^{2}$ \\ and Bob Olsson ${ }^{4}$
}

\begin{abstract}
Background: MicroRNA are small noncoding RNA molecules that are involved in the control of gene expression. To investigate the role of microRNA in multiple sclerosis (MS), we performed genome-wide expression analyses of mRNA and microRNA in T-cells from MS patients and controls.

Methods: Heparin-anticoagulated peripheral blood was collected from MS-patients and healthy controls followed by isolation of T-cells. MicroRNA and RNA from T-cells was prepared and hybridized to Affymetrix miR 2.0 array and Affymetrix U133Plus 2.0 Human Genome array (Santa Clara, CA), respectively. Verifications were performed with real-time polymerase chain reaction (PCR) and enzyme-linked immunosorbent assay (ELISA).

Results: We identified 2,452 differentially expressed genes and 21 differentially expressed microRNA between MS patients and controls. By Kolmogorov-Smirnov test, 20 of 21 differentially expressed microRNA were shown to affect the expression of their target genes, many of which were involved in the immune system. Tumor necrosis factor ligand superfamily member 14 (TNFSF14) was a microRNA target gene significantly decreased in MS. The differential expression of mir-494, mir-197 and the predicted microRNA target gene TNFSF14 was verified by real-time PCR and ELISA.
\end{abstract}

Conclusion: These findings indicate that microRNA may be important regulatory molecules in T-cells in MS.

Keywords: Autoimmunity, T-cell, Microarray, MicroRNA

\section{Background}

Multiple sclerosis (MS) is a chronic inflammatory autoimmune disease characterized by demyelination, astrogliosis and damage to oligodendrocytes and axons in the CNS. The underlying cause and etiology of MS is incompletely understood, but some evidence points to a multifactorial origin involving both central and peripheral immunological tolerance mechanisms. An inappropriate T-cell response to myelin antigens is probably a fundamental mechanism in the MS pathophysiology [1,2].

MicroRNA are 19-25 base pair long single stranded RNA nucleotides. They are evolutionary conserved and are increasingly regarded as being involved in all aspects of cellular function in a wide range of eukaryotic organisms [3]. Approximately $33 \%$ of the human genes are

\footnotetext{
* Correspondence: margareta.jernas@medic.gu.se

${ }^{1}$ Department of Molecular and Clinical Medicine, The Sahlgrenska Academy at University of Gothenburg, Gothenburg, Sweden

Full list of author information is available at the end of the article
}

estimated to be regulated by microRNA and a single microRNA can potentially regulate multiple mRNA targets (in average 200) [4,5]. There are more than 1500 human microRNA identified (http://www.mirbase.org) [6] and they are associated with major pathologies such as autoimmune diseases [7-9] and cancer [10]. However, the in vivo function of most microRNA is largely unknown.

MicroRNA are highly expressed in cells of the immune system $[11,12]$ and they are involved in numerous pathways of both the innate and the adaptive immune system [3,13-16]. It has been reported that microRNA are critical for the maintenance of immunological tolerance; deletion of the enzymes Dicer- and Drosha that are involved in the generation of microRNAs, results in T-cell abnormalities and autoimmune diseases $[17,18]$. The microRNA transcriptome of immune cell subsets are distinct, suggesting that naïve, effector and central memory $\mathrm{T}$ cell $[19]$ and regulatory $\mathrm{T}$ cell function $[17,18,20]$ are dependent on microRNA regulation. Furthermore, 
microRNA are reported to be important regulatory factors in the differentiation of T cells [21] and associated with activation of $\mathrm{T}$ cell-mediated immune responses [22]. Several publications have addressed the role of individual microRNAs in MS [23-34]. However, very few have performed large scale unbiased studies. Furthermore, most studies have investigated microRNA expression in peripheral blood mononuclear cells (PBMC). $\mathrm{PBMC}$ is a compartment with heterogeneous cell composition due to individual biological variation or disease state. Therefore, the aim of this study was to identify differentially expressed microRNA and target mRNA in T-cells from MS-patients using global DNA microarray analyses.

\section{Methods}

\section{Participants}

All individuals involved in this study gave informed consent. The study was approved by the regional ethics committee in Gothenburg, Sweden.

The ten relapsing remitting MS (RRMS) subjects in the mRNA analysis (six males and four females; age $38.1 \pm 11.7$ years) have previously been described [35] For the microRNA experiment, heparin-anticoagulated peripheral blood was obtained from 11 (1 male, $10 \mathrm{fe}-$ males, mean age $42.9 \pm 3.4$ years) relapsing-remitting MS (RRMS) patients according to the McDonald criteria $[36,37]$ who were on treatment with beta interferon (Additional file 1: Table S1). The disease duration was $10.6 \pm 2.1$ years and neurological deficits were scored with Expanded Disability Status Scale (EDSS) [38] and median was 2.1 (range 0-6). Nine healthy individuals served as controls ( 4 males, 5 females mean age $42.6 \pm 13.6)$.

For the verification of microRNA experiments by realtime PCR heparin-anticoagulated peripheral blood was collected from 16 RRMS patients (1 male, 15 females, mean age $45.1 \pm 2.7$ ) according to the McDonald criteria $[36,37]$. The disease duration was $12.0 \pm 1.9$ years and the median EDSS score was 2.4 (range 0-6). Twelve healthy individuals served as controls (6 males, 6 females, mean age $44.4 \pm 12.0$ ). For the verification of mRNA expression of TNFSF14 by real-time PCR analysis, the same patients were used, however there were only RNA left from 13 patients (Additional file 1: Table S1).

For the ELISA experiment, peripheral blood without anticoagulantia was collected from 16 RRMS patients ( 1 male, 15 females, mean age $45.1 \pm 2.7$ ) according to the McDonald criteria [36,37]. The disease duration was $12.0 \pm 1.9$ years and the median EDSS score was 2.4 (range 0-6) (Additional file 1: Table S1). Twenty healthy individuals served as controls (6 males, 14 females, mean age $38.4 \pm 12.0$ ).

\section{Isolation of T-cells and preparation of RNA}

The isolation of T-cells has previously been described [39]. In brief, peripheral blood mononuclear cells (PBMCs) were separated from heparinized blood immediately after collection, by density gradient centrifugation using Ficoll-Paque PLUS (GE Healthcare, Uppsala, Sweden). After removal of CD14 ${ }^{+}$cells by magnetic microbeads, T-cells were positively selected using $\mathrm{CD}^{+}$magnetic microbeads, according to the manufacturer's recommendations (MACS, Miltenyi Biotec, Surrey, UK). The purity of isolated cells was thereafter determined by flow cytometry; 93.6-96.2\% of the cells were CD3+ T-cells, with no significant differences between the study groups. The cells were frozen and stored at $-80^{\circ} \mathrm{C}$. RNA was isolated from the $\mathrm{CD}^{+}$T-cells using the Chomczynski method [40]. For the microRNA analysis the RNA was precipitated using isopropanol overnight. For the DNA microarray analysis the RNA was further purified using RNeasy MinElute clean-up (Qiagen, Hilden, Germany). The RNA concentration was measured with a Nanodrop spectrophotometer and the A260/A280 ratio was $1.8-2.0$. The quality of the RNA was verified by agarose gel electrophoresis for the DNA microarray analysis. The mean quantity of total RNA from T-cells in peripheral blood was $5.8 \mu \mathrm{g}$ (range 1.2-10.3 $\mu \mathrm{g}$ ) for the microRNA analysis and for the DNA microarray analysis $36.8 \mu \mathrm{g}(1.08-104.88 \mu \mathrm{g})$.

\section{Labeling and hybridization to microRNA 2.0 microarrays} 1000 ng RNA from T-cells were biotin labeled using the FlashTag Biotin HSR kit (Genisphere, Hatfield, PA) according to the manufacturer's instructions. The labeled microRNA was controlled using the Enzyme Linked Oligosorbent Assay (ELOSA) step (Genisphere), following the manufacturer's instructions. All samples showed expected labeling and the resulting targets were hybridized to miR 2.0 arrays (Affymetrix), containing 15,644 microRNA probe sets from the miRBASE v15 (http://microrna.sanger.ac.uk). The arrays recognize microRNA from 131 organisms, including human small nucleolar RNA such as snoRNA and small Cajal bodyspecific RNA (scaRNA) from the Ensembl Archive (www.ensembl.org/biomart/martview) and snoRNAbase (http://www-snorna.biotoul.fr/info.php). The arrays were washed and processed on a Fluidics Station 450 and scanned with a confocal laser scanner (GeneChip Scanner 3000, Affymetrix) according to the manufacturer's instructions.

\section{Labeling and hybridization to U133Plus 2.0 DNA microarrays}

As previously described 5.0 ug RNA was reverse transcribed into cDNA (Superscript II, Invitrogen, Carlsbad, CA) [35]. Biotin-labeled target cRNA was prepared from 
cDNA by in vitro transcription (Enzo Diagnostics, Farmingdale, NY) and hybridized to Human Genome HG-U133 plus 2.0 arrays (Affymetrix, Santa Clara, CA), containing 54,675 probe sets, as recommended in the Affymetrix Gene Chip Expression Analysis manual. Arrays were scanned with a confocal laser scanner (GeneChip Scanner 3000, Affymetrix) and visualized using GCOS. These experiments comply with Minimum Information About a Microarray Experiment (MIAME) [41].

\section{Data analysis of miR_2.0 microarrays}

Data from the microarrays were analyzed with Affymetrix microRNA QC Tool according to the manufacturers' instructions. Robust Multi-array Analysis (RMA) was used for normalization. To be included in the analysis the probe sets had to be detected in more than $50 \%$ of the patients and controls. Thereafter, the differential gene expression was evaluated using Student's t-test (two tailed).

\section{Data analysis of DNA microarrays U133Plus 2.0}

The DNA and microRNA microarrays (GSE43592) were processed and normalized together using Probe Logarithmic Intensity Error (PLIER) method [42]. Differences in gene expression between the groups were investigated by Student's $t$-test (two tailed) using linear models together with empirical Bayes [43]. P-values from the student's $t$-test were transformed into $\mathrm{Q}$-values through the correction for multiple testing [44]. The Q-values were overlaid on Gene Ontology (GO) networks and then a reporter algorithm $[45,46]$ was used to evaluate the enrichment $\mathrm{p}$-value of each GO term. GO terms that had enrichment $\mathrm{P}$-values $<0.05$ were selected in the construction of a heatmap as illustrated in Figure 1. The analyses were performed using piano package [47] under the $\mathrm{R}$ software environment.

\section{Computational methods to identify microRNA functions and mRNA targets}

The most commonly used microRNA database mirBase (http://www.mirbase.org) released in November 2011 [6], including over 21643 mature microRNA products in 168 species, was used to identify microRNA functions and target mRNAs. Multiple computational methods are developed to predict microRNA target sites [48] and in general, target prediction algorithms focus on the complementarities between the microRNA and the potential targets around the "seed" sequence, heteroduplex free energy of binding, location and size of internal loops and bulges, and accessibility of the target site as predicted by RNA folding. To predict mRNA targets to the differentially expressed microRNAs in the present study, we used TargetScan [49] (http:// www.targetscan.org) and Miranda [50] (http://www.
microrna.org/microrna/getDownloads.do). However, there are some evidence that perfect seed pairing may not necessarily be a reliable prediction for microRNAmRNA interaction since these bioinformatics tools do not take into account the secondary structure of the mRNA which may affect the microRNA target recognition [51]. Therefore, as a way to achieve the high confidence microRNA-mRNA associations and evaluate the impact of each microRNA on the gene expression, the predicted microRNA target genes of each microRNA were identified and combined with mRNA transcriptome from MS patients and controls. Kolmogorov-Smirnov test was employed to evaluate the impact of each microRNA on gene expression between MS patients and controls (the test was performed over cumulative fraction of gene expression fold changes of specific microRNA targets and background, which is the rest of the genes that do not contain the targets of specific microRNA $[5,49])$. The results are reported in Table 1 . The identified target genes were cross referenced against the differentially expressed mRNAs that differed between MS patients and controls.

\section{Real-time PCR analysis of microRNA expression}

Mir-494 and mir-197 were selected for verification and specific Taqman ${ }^{\oplus}$ MicroRNA assays (Applied Biosystems, Life Technology, Foster City, CA) were used. Reverse transcriptase (RT) reactions contained 10 ng RNA, 5 X stem-loop RT primer, $10 \times$ RT buffer, $100 \mathrm{mM}$ dNTPs, $50 \mathrm{U} / \mu \mathrm{l}$ MultiScribe reverse transcriptase and $20 \mathrm{U} / \mu \mathrm{l}$ RNase inhibitor (Applied Biosystems). The reactions were incubated for $30 \mathrm{~min}$ at $16^{\circ} \mathrm{C}, 30 \mathrm{~min}$ at $42^{\circ} \mathrm{C}$, $5 \mathrm{~min}$ at $85^{\circ} \mathrm{C}$. The High Capacity RNA-to-cDNA Kit (Applied Biosystems) was used for the housekeepinggene RPLPO. All reverse transcriptase reactions were run in duplicate.

Real-time PCR was performed using a standard TaqMan ${ }^{\oplus}$ PCR kit protocol on an Applied Biosystems 7900HT Sequence Detection System. The PCR included the RT product, $1 \times$ TaqMan $^{\odot}$ Universal PCR Master Mix and TaqMan $^{\oplus}$ Small RNA assay $(20 \times)$. The reactions were incubated at $95^{\circ} \mathrm{C}$ for $10 \mathrm{~min}$, followed by 40 cycles of $95^{\circ} \mathrm{C}$ for $15 \mathrm{~s}$ and $60^{\circ} \mathrm{C}$ for $1 \mathrm{~min}$. The cycle threshold $(\mathrm{Ct})$ value of the house-keeping gene RPLPO was subtracted from the corresponding $\mathrm{Ct}$ value for mir494 and mir-197 resulting in the $\Delta \mathrm{Ct}$ value and relative quantification was calculated using the $\left(2^{-\Delta \Delta C T}\right)$ formula [52]. Differences were analyzed by Student's $t$-test (two tailed).

\section{Real-time PCR analysis of mRNA expression of TNFSF14}

Reagents for real-time PCR analysis of TNFSF14, such as High Capacity RNA-to-cDNA Kit and TaqMan Universal PCR Master Mix, were obtained from Applied Biosystems by Life Technologies (Carlsbad, CA) and used according to 


\section{Enrichment score $\begin{array}{llllllll}-6 & -4 & -2 & 0 & 2 & 4 & 6\end{array}$}

GO:0050672 negative regulation of lymphocyte proliferation (12) GO:0034145 positive regulation of toll-like receptor 4 signaling pathway (6) GO:0048539 bone marrow development (7)

GO:0033081 regulation of T cell differentiation in thymus (8) GO:0050871 positive regulation of $B$ cell activation (6) GO:0001779 natural killer cell differentiation (17) GO:0048305 immunoglobulin secretion (10) GO:0031295 T cell costimulation (32) GO:0030224 monocyte differentiation (13) GO:0002752 cell surface pattern recognition receptor signaling pathway (6) GO:0002639 positive regulation of immunoglobulin production (16) GO:0030595 leukocyte chemotaxis (14) GO:0002437 inflammatory response to antigenic stimulus (8) GO:0002329 pre-B cell differentiation (9) GO:0001773 myeloid dendritic cell activation (6) GO:0033151 V(D)J recombination (22) GO:0045637 regulation of myeloid cell differentiation (9) GO:0016064 immunoglobulin mediated immune response (24) GO:0050869 negative regulation of B cell activation (10) GO:0045059 positive thymic T cell selection (17) GO:0043353 enucleate erythrocyte differentiation (17) GO:0042110 T cell activation (98) GO:0033077 T cell differentiation in thymus (49) GO:0060754 positive regulation of mast cell chemotaxis (7) GO:0002230 positive regulation of defense response to virus by host (20) GO:0030219 megakaryocyte differentiation (13) GO:0046642 negative regulation of alpha-beta T cell proliferation (11) GO:0045652 regulation of megakaryocyte differentiation (7) GO:0002829 negative regulation of type 2 immune response (11) GO:0048541 Peyer's patch development (17) GO:0043320 natural killer cell degranulation (8) GO:0032816 positive regulation of natural killer cell activation (12) GO:0042102 positive regulation of T cell proliferation (61) GO:0050798 activated T cell proliferation (15) GO:0045671 negative regulation of osteoclast differentiation (29) GO:0030890 positive regulation of B cell proliferation (74)

GO:0045621 positive regulation of lymphocyte differentiation (9) GO:0050901 leukocyte tethering or rolling (11) GO:0002860 positive regulation of NK cell mediated cytotoxicity against tumor cell (11) GO:0050777 negative regulation of immune response (23)

GO:0050687 negative regulation of defense response to virus (11) GO:0045656 negative regulation of monocyte differentiation (7) GO:0043029 T cell homeostasis (43)

GO:0045638 negative regulation of myeloid cell differentiation (10) GO:0045647 negative regulation of erythrocyte differentiation (11) GO:0045580 regulation of T cell differentiation (12)

GO:0045577 regulation of B cell differentiation (10) GO:0050863 regulation of $T$ cell activation (8) GO:0045576 mast cell activation (13) GO:0048302 regulation of isotype switching to $\lg G$ isotypes (8) GO:0045061 thymic T cell selection (9) GO:0002821 positive regulation of adaptive immune response (7) GO:0006955 immune response (774) GO:0050868 negative regulation of T cell activation (19) GO:0046638 positive regulation of alpha-beta T cell differentiation (17) $\mathrm{GO}: 0030217$ T cell differentiation (75) GO:0030217 T cell differentiation (75) GO:0030101 natural killer cell activation (24)

GO:0042267 natural killer cell mediated cytotoxicity (16)

Figure 1 In the DNA microarray analysis we identified 2452 differentially expressed genes $(Q<0.05 ; P L I E R)$ in peripheral blood T-cells that differed between MS patients and healthy controls. In order to identify which biological processes the differentially expressed genes belonged to we used GO. Two hundred and fifty-six genes were classified as immune-related according to GO [53]. The number of genes in each category is shown in parenthesis. The enrichment score $(-\log 10$ (enrichment $P$-values)) is shown in red for overrepresented gene ontology terms and in blue for the ones underrepresented in MS patients compared with controls. All gene ontology terms that had $P$-values $<0.05$ are shown.

the manufacturer's protocol. RPLPO was used as reference to normalize the expression levels between samples. cDNA was synthesized from 200 ng of total RNA in a reaction volume of $20 \mu \mathrm{l}$. Specific products were amplified and detected with the ABI Prism 7900HT Sequence Detection System (Applied Biosystems) using default cycle parameters. All samples were analysed in triplicates. The relative comparative $C_{\mathrm{T}}$ method was used to analyse the real-time PCR data [52]. Differences were analyzed by Students T-test.

\section{Immunoassay analysis of TNFSF14}

Serum levels of TNFSF14 were analyzed with a commercial ELISA from R\&D systems (Minneapolis, MN). Intra-assay coefficient of variation was $5.1 \%$ and the limit of detection was $31 \mathrm{ng} / \mathrm{l}$. Differences were analyzed by Students T-test.

\section{Statistics}

The statistics for each analysis is given above in their subsections. $P$-values $\leq 0.05$ were considered significant 
Table 1 Differentially expressed small nucleolar RNA in T-cells between MS patients and controls

\begin{tabular}{|c|c|c|}
\hline Small nucleolar RNA & Fold change MS/Control & P-value \\
\hline mgU12-22-U4-8_s_st & 0.66 & 0.037 \\
\hline mgU2-25-61_s_st & 0.84 & 0.041 \\
\hline SNORD119_st & 0.77 & 0.03 \\
\hline U104_st & 0.77 & 0.027 \\
\hline U105_st & 0.83 & 0.046 \\
\hline U105B_st & 0.39 & 0.023 \\
\hline U17b_st & 0.53 & 0.025 \\
\hline U17b_x_st & 0.58 & 0.02 \\
\hline U27_st & 0.57 & 0.004 \\
\hline U27_x_st & 0.55 & 0.01 \\
\hline U31_st & 0.71 & 0.031 \\
\hline U31_x_st & 0.69 & 0.035 \\
\hline U42B_x_st & 0.79 & 0.042 \\
\hline U56_st & 0.43 & 0.031 \\
\hline U56_x_st & 0.33 & 0.005 \\
\hline U58A_st & 0.85 & 0.02 \\
\hline U59A_st & 0.76 & 0.014 \\
\hline U61_st & 0.66 & 0.01 \\
\hline U79_st & 0.81 & 0.028 \\
\hline U80_st & 0.70 & 0.018 \\
\hline U83_st & 0.65 & 0.02 \\
\hline U83A_x_st & 0.80 & 0.03 \\
\hline U84_x_st & 0.75 & 0.029 \\
\hline v11_hsa-miR-768-3p_st & 0.74 & 0.028 \\
\hline v11_hsa-miR-768-5p_st & 0.86 & 0.025 \\
\hline ACA16_st & 0.76 & 0.014 \\
\hline ACA16_x_st & 0.69 & 0.002 \\
\hline ACA24_x_st & 0.68 & 0.008 \\
\hline ACA44_s_st & 0.50 & 0.048 \\
\hline ACA48_x_st & 0.68 & 0.005 \\
\hline ACA54_st & 0.45 & 0.003 \\
\hline ACA7_s_st & 0.40 & 0.002 \\
\hline ACA7B_s_st & 0.52 & 0.01 \\
\hline E3_x_st & 0.73 & 0.016 \\
\hline ENSG00000201009_S_St & 0.58 & 0.033 \\
\hline ENSG00000206903_S_st & 0.54 & 0.031 \\
\hline ENSG00000206913_S_st & 0.40 & 0.002 \\
\hline ENSG00000212615_x_St & 0.77 & 0.014 \\
\hline ENSG00000239031_st & 1.15 & 0.039 \\
\hline ENSG00000252049_st & 1.10 & 0.046 \\
\hline HBII-210_st & 0.42 & 0.028 \\
\hline HBII-436_st & 0.81 & 0.018 \\
\hline HBII-55_st & 0.62 & 0.04 \\
\hline
\end{tabular}

Table 1 Differentially expressed small nucleolar RNA in T-cells between MS patients and controls (Continued)

\begin{tabular}{lll}
\hline HBII-85-17_x_st & 0.85 & 0.031 \\
HBII-85-29_st & 0.65 & 0.004 \\
HBII-85-3_x_st & 0.81 & 0.003 \\
HBII-85-9_x_st & 0.87 & 0.043 \\
HBII-99_st & 0.51 & 0.011 \\
hp_hsa-let-7d_st & 0.90 & 0.044 \\
hp_hsa-mir-423_s_st & 0.52 & 0.023 \\
\hline Displayed is the fold change in expression between MS patients and controls.
\end{tabular}

and all data are presented as mean \pm SEM unless otherwise stated.

\section{Results}

Differentially expressed microRNA in T-cells between MS patients and controls

To identify T-cell microRNA with a differential expression between MS patients and controls we analyzed approximately 1000 microRNA with microarray analysis. On the microarrays were also probes for a large number of small snoRNA and scaRNA. Twenty-one microRNA had decreased expression in peripheral blood T-cells in MS patients compared with controls (Table 2). The mature microRNA sequences are given in (Additional file 1: Table S2). In addition, 50 small nucleolar RNA such as snoRNA and scaRNAs were differently expressed in T-cells between MS patients and controls (Table 1).

\section{Differentially expressed mRNA in T-cells between MS patients and controls}

DNA microarray analysis was used to identify differentially expressed T-cell genes between MS patients and controls. In the DNA microarray analysis we identified 2452 differentially expressed genes $(Q<0.05$; PLIER) in peripheral blood T-cells that differed between MS patients and healthy controls. In order to identify which biological processes the differentially expressed genes belonged to we used GO. Two hundred and fifty-six genes were classified as immune-related according to GO [53] and over or under represented biological processes for these genes are shown in Figure 1.

\section{Identification of differentially expressed target genes of microRNA}

To better understand the role of the differentially expressed microRNA in MS patients we first identified the predicted target genes for each of the microRNA using the databases TargetScan and Miranda. Second, to investigate if the significantly changed microRNA had any effect on gene 
Table 2 Impact of differentially expressed microRNA on gene expression in T-cells between MS patients and controls

\begin{tabular}{|c|c|c|c|c|}
\hline \multirow[t]{2}{*}{ microRNA } & \multicolumn{2}{|c|}{ microRNA microarray } & \multicolumn{2}{|c|}{ Impact of microRNA on its targets (mRNA microarray) } \\
\hline & Fold change MS/Control & P-value & TargetScan & Miranda \\
\hline hsa-miR-494 & 0.14 & $3.1 \times 10^{-05}$ & $1.2 \times 10^{-24}$ & $6.0 \times 10^{-81}$ \\
\hline hsa-miR-15b & 0.14 & $2.5 \times 10^{-03}$ & $4.1 \times 10^{-34}$ & $5.5 \times 10^{-15}$ \\
\hline hsa-miR-30c & 0.15 & $7.7 \times 10^{-04}$ & $2.8 \times 10^{-13}$ & $5.0 \times 10^{-58}$ \\
\hline hsa-miR-23a & 0.16 & $7.8 \times 10^{-03}$ & $2.2 \times 10^{-23}$ & $9.8 \times 10^{-63}$ \\
\hline hsa-miR-197 & 0.19 & $5.2 \times 10^{-06}$ & $1.6 \times 10^{-12}$ & $1.2 \times 10^{-06}$ \\
\hline hsa-miR-1260b & 0.21 & $9.4 \times 10^{-07}$ & NA & $2.3 \times 10^{-16}$ \\
\hline hsa-miR-125a-5p & 0.22 & $8.2 \times 10^{-03}$ & $1.2 \times 10^{-43}$ & $5.3 \times 10^{-13}$ \\
\hline hsa-miR-361-5p & 0.24 & $1.4 \times 10^{-02}$ & $1.8 \times 10^{-15}$ & $3.9 \times 10^{-32}$ \\
\hline hsa-miR-320d & 0.26 & $2.8 \times 10^{-03}$ & $2.0 \times 10^{-09}$ & $7.4 \times 10^{-36}$ \\
\hline hsa-miR-423-3p & 0.26 & $1.6 \times 10^{-02}$ & $5.0 \times 10^{-13}$ & $1.8 \times 10^{-03}$ \\
\hline hsa-miR-1280 & 0.29 & $4.7 \times 10^{-03}$ & $8.2 \times 10^{-56}$ & $8.6 \times 10^{-04}$ \\
\hline hsa-miR-663 & 0.32 & $3.5 \times 10^{-03}$ & $5.9 \times 10^{-70}$ & $1.8 \times 10^{-28}$ \\
\hline hsa-miR-423-5p & 0.33 & $2.6 \times 10^{-02}$ & $6.1 \times 10^{-96}$ & $5.7 \times 10^{-36}$ \\
\hline hsa-miR-99b & 0.36 & $2.4 \times 10^{-02}$ & $3.4 \times 10^{-04}$ & $7.6 \times 10^{-03}$ \\
\hline hsa-miR-339-5p & 0.37 & $4.9 \times 10^{-02}$ & $1.5 \times 10^{-35}$ & $2.5 \times 10^{-07}$ \\
\hline hsa-let-7a & 0.37 & $2.9 \times 10^{-02}$ & $1.9 \times 10^{-04}$ & $3.2 \times 10^{-09}$ \\
\hline hsa-miR-1979 & 0.38 & $1.2 \times 10^{-02}$ & NA & $8.1 \times 10^{-09}$ \\
\hline hsa-miR-3178 & 0.39 & $1.0 \times 10^{-02}$ & NA & NS \\
\hline hsa-miR-625 & 0.41 & $3.2 \times 10^{-02}$ & $3.6 \times 10^{-62}$ & $2.3 \times 10^{-09}$ \\
\hline hsa-miR-150 & 0.65 & $3.7 \times 10^{-02}$ & $2.1 \times 10^{-68}$ & $2.1 \times 10^{-11}$ \\
\hline hsa-miR-3153 & 1.14 & $4.5 \times 10^{-02}$ & NA & $2.4 \times 10^{-09}$ \\
\hline
\end{tabular}

To investigate the impact of the significantly changed microRNAs on gene expression in T-cells we performed Kolmogorov-Smirnov test using the target genes identified in TargetScan and Miranda. NS: not significant, NA: not available in the database. Displayed is the fold change in expression between MS patients and controls.

expression we performed Kolmogorov-Smirnov test using the target genes identified in TargetScan and Miranda on the gene expression data. The results showed that there were some differences between the two databases TargetScan and Miranda but that in most cases the same results were obtained, i.e. that the differently expressed microRNA did indeed significantly affect the gene expression (Table 2). Third, to identify which of the differentially expressed genes that were indeed target genes of the differentially expressed microRNA we compared the list of microRNA target genes with our list of differentially expressed genes between MS and controls. This resulted in 920 genes. Fourth, these 920 genes were classified according GO and 100 genes were classified as being involved in immune processes. The top 25 genes with increased and decreased expression between MS and controls, respectively, are shown in Additional file 1: Table S3. They were further analyzed using functional module enrichment [54] based on Immune System Gene Ontology [53] which resulted in 21 modules that were enriched with separate functions (see following list and Additional file 1: Figure S1).
List of functional module enrichment based on Immune System Gene Ontology on target genes of differentially expressed microRNA between MS patients and controls:

Antigen processing and presentation of exogenous peptide antigen via MHC class I, TAP-dependent

$\mathrm{T}$ cell migration

Megakaryocyte differentiation

Toll-like receptor 3 signaling pathway

Regulation of response to interferon-gamma

Natural killer cell mediated immunity

Negative regulation of lymphocyte activation

Negative regulation of inflammatory response to

antigenic stimulus

Regulation of inflammatory response to antigenic stimulus

Thymic T cell selection

Natural killer cell differentiation

$\mathrm{V}(\mathrm{D})$ J recombination

Megakaryocyte differentiation

Negative regulation of erythrocyte differentiation

Megakaryocyte differentiation 
Negative regulation of type 2 immune response

Dendritic cell chemotaxis

Natural killer cell activation

Regulation of defense response to virus

Positive regulation of monocyte chemotaxis

Regulation of toll-like receptor 3 signaling pathway

The interactions between the 20 microRNA and the 100 genes are shown in Figure 2.

\section{Verification of a differently expressed microRNA using real-time PCR}

To verify the results from the DNA microarray analysis we selected mir-494 and mir-197 because they were among the microRNAs that had the largest fold change in expression between MS patients and controls of all the microRNA (Table 1). We analyzed the expression of mir-494 and mir-197 with real-time PCR and confirmed that the expression was significantly decreased in MS patients compared with controls $(P=0.02$ and $P=0.04$; Figure 3A-B).

\section{Verification of TNFSF14 using real-time PCR}

To verify the results in the DNA microarray analysis and predicted mRNA target analysis, we analyzed the expression of TNFSF14 with real-time PCR and confirmed that the expression was significantly decreased in MS patients compared with controls $(P=0.05$; Figure 4$)$.

\section{Serum levels of TNFSF14 in MS compared with healthy controls}

To test whether changes in microRNA expression were accompanied by changes of corresponding proteins we determined serum levels of TNFSF14 in MS patients and controls. The serum level of this protein was found to be significantly decreased in MS patients compared with controls $(P=0.05$; Figure 5$)$.

\section{Discussion}

To explore genes and mechanisms involved in MS we performed global microarray analyses of mRNA and microRNA in T-cells from MS patients and controls. We found 2,452 genes and 21 microRNA that differed significantly in expression between MS patients and controls. Of

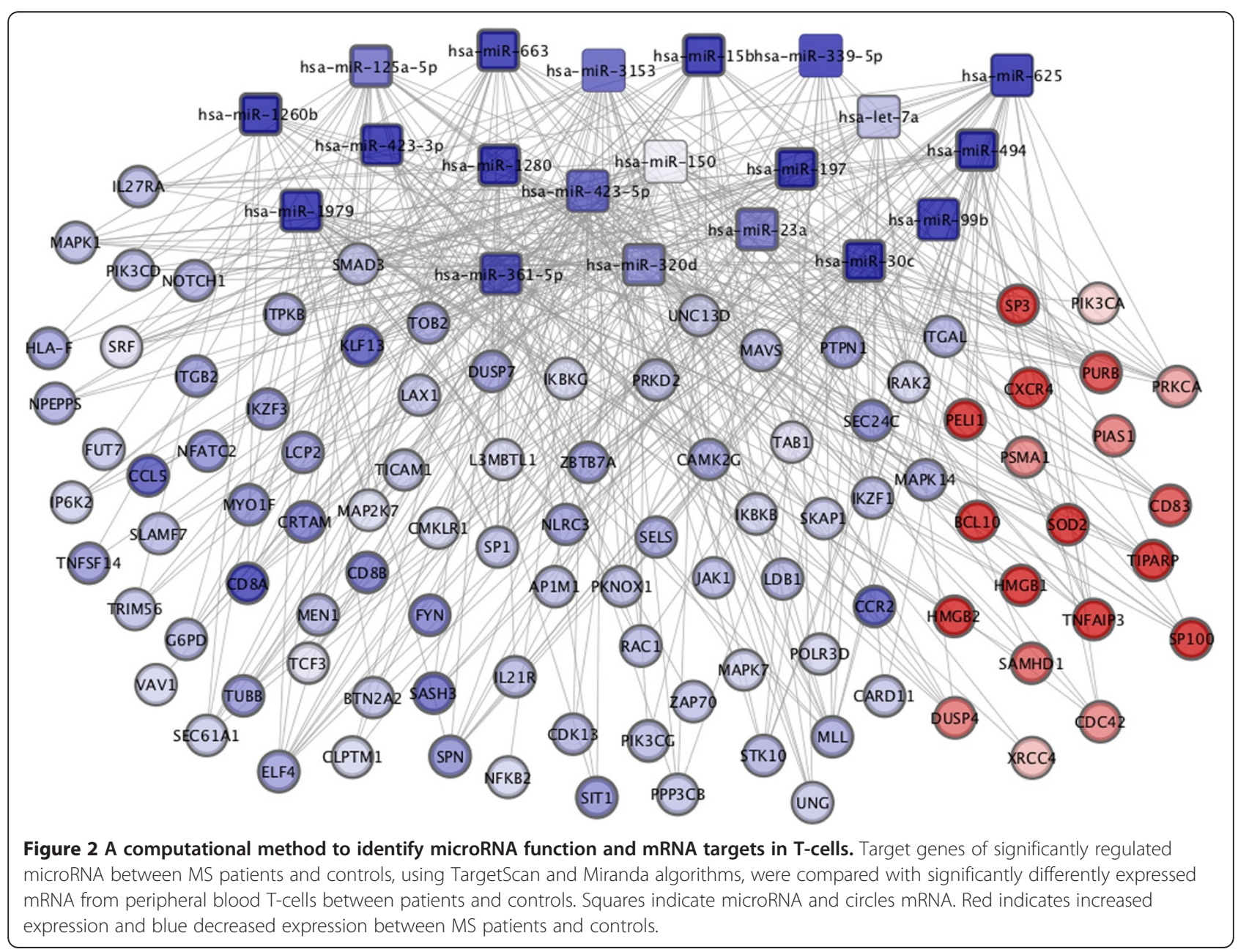



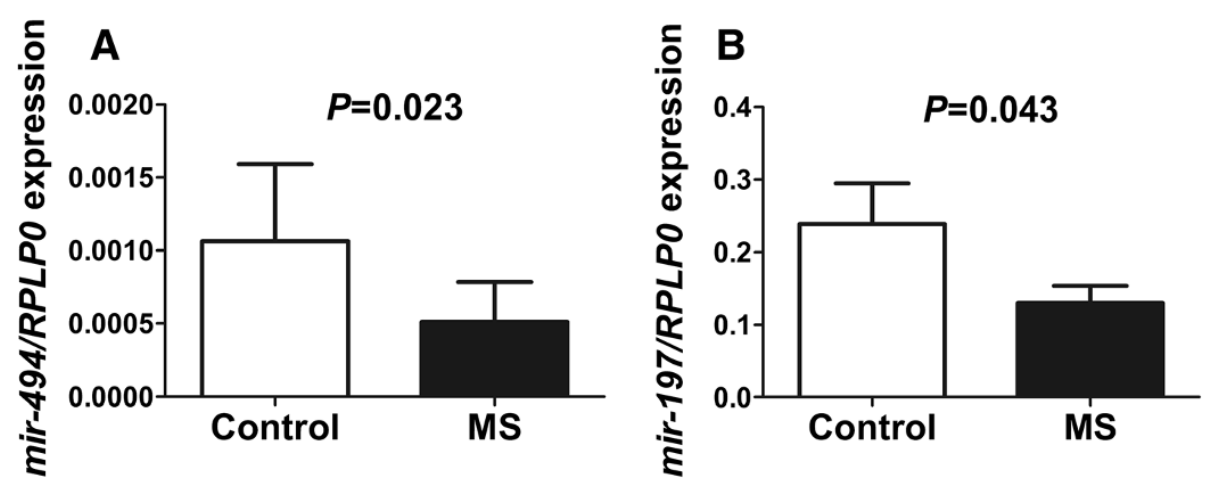

Figure 3 Verification of the differential expression of A) mir-494 and B) mir-197 between MS patients $(n=16)$ and healthy controls $(n=12)$ by real-time PCR. Data are presented as mean \pm SEM.

these, 20 microRNA significantly affected the expression of their target genes. When the microRNA target genes were cross-referenced against the genes that differed in expression between MS patients and controls 920 genes were identified and 100 were involved in the immune system. To better understand the role of the target genes we clustered the genes involved in the immune system using GO. The significantly enriched immune processes observed between MS and controls, points to well known processes within autoimmunity. Four of the 21 (mir-150, mir-15b, mir-1979 and mir-23a) identified microRNA in this study have already been linked to MS, however, not in $\mathrm{CD}^{+}$T-cells $[27,28,34,55]$. We also found 50 small nucleolar RNAs such as snoRNAs and scaRNAs that were differently expressed in T-cells between MS patients and controls. However, in this manuscript we have focused on microRNA since the amount of information concerning

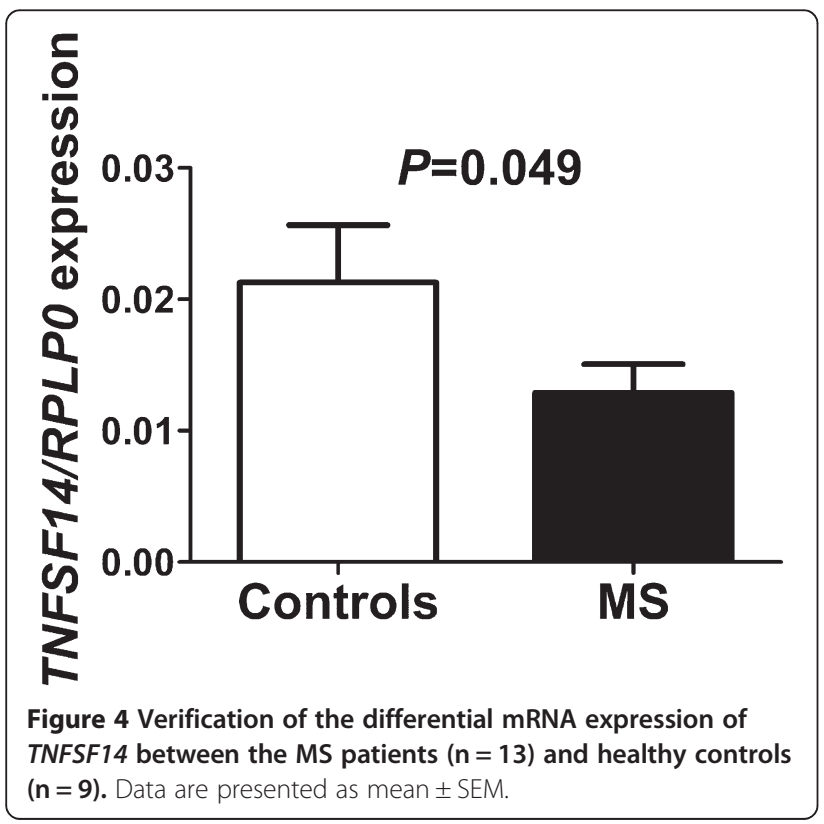

the smaller molecules such as snoRNA is scarce to say the least.

We found several genes that were involved in immunological pathways previously associated with MS such as ITGAM, CD8A, CD8B, CCL5, CCR2, TGFBR1 and TNFSF14 among the top genes regulated by the differentially expressed microRNA. ITGAM is an integrin involved in leukocyte migration that is expressed on T-cells and other leukocytes [56]. ITGAM expression is critical on T-cells and phagocytes for the development of EAE in mice [57]. CD8A and CD8B are the two genes that codes for the subunits of CD8 which is specifically expressed on cytotoxic T-cells which are involved in major histocompatibility class I immunosurveillance. CCL5, also known as RANTES, is a chemokine and T-cells from MS patients have been shown to have increased migration towards CCL5 compared with T-cells from healthy controls [58]. Furthermore, treatment with anti-CCL5 antibodies in EAE mice prevented leukocyte adhesion but not rolling [59] and a selective antagonist against one of the receptors for CCL5, namely CCR1, abrogated clinical disease signs in EAE rats [60]. CCR2 is the receptor for

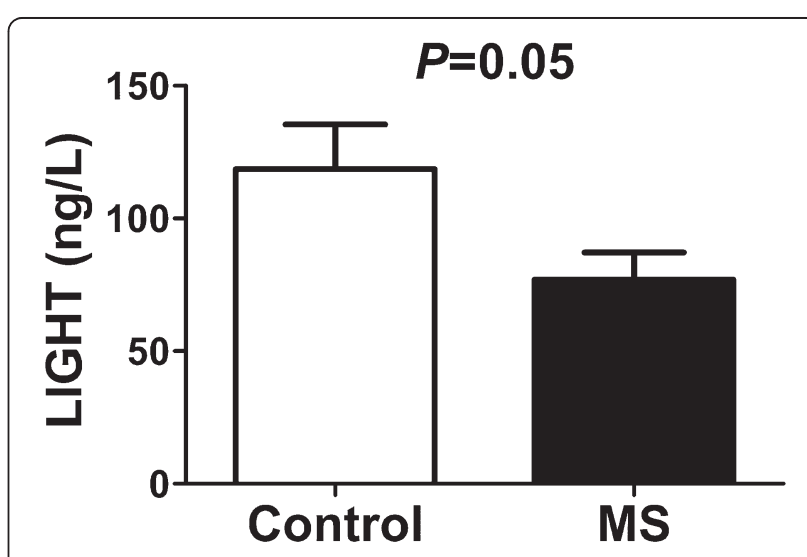

Figure 5 Verification of the protein levels of TNFSF14 between the MS patients $(n=16)$ and healthy controls $(n=20)$. Data are presented as mean \pm SEM. 
CCL2, also known as monocyte chemoattractant protein 1 (MCP-1). Anti-CCL2 treatment prevented the development of paralysis in EAE mice [61] and leukocyte adhesion [59]. TGFBR1 is the receptor for TGF- $\beta 1$ and administration of TGF- $\beta 1$ protects and even improves the clinical course of EAE when given during ongoing disease [62]. Furthermore, deletion of TGF- $\beta 1$ in mice leads to an early death caused by massive tissue infiltration of lymphocytes and macrophages resembling autoimmunity [63].

TNFSF14 is a newly identified risk gene for MS along with its receptor TNFRSF14 (HVEM). A recent study showed that membrane-bound TNFSF14 is important for $\mathrm{CD}^{+}$memory T-cell survival [64]. Membrane-bound TNFSF14 is a co-stimulatory molecule [65] which has diverse stimulatory effects on the immune system. Over-expression of the membrane-bound form leads on T-cells leads to autoimmunity in mice [66-68]. It has also been implicated in asthma and tumor response $[69,70]$. In contrast, the soluble form of TNFSF14 has been shown to act as an inhibitor of activation [71-74]. We chose TNFSF14 for verification by real-time PCR and ELISA because it had a high expression level and the fact that there was a soluble form of the protein. Indeed, we found that both the mRNA and the protein expression of the microRNA target gene TNFSF14 was decreased in MS compared with controls.

Limitations of this study include the lack of naïve MS patients and the lack of gender matching.

\section{Conclusion}

These findings indicate that microRNA may be important regulatory molecules in T-cells in MS.

\section{Reviewer link to access microarray data}

http://www.ncbi.nlm.nih.gov/geo/query/acc.cgi?

token=blapdgogguqwklw\&acc=GSE43592.

\section{Additional file}

Additional file 1: Table S1. Patient characteristics in the microRNA analysis. Table S2. Significantly regulated microRNAs in T-cells between MS patients and controls. Table S3. Differentially expressed mRNAs in T-cells between MS patients and controls. Figure S1. The identified target genes of the differentially expressed microRNA were cross referenced against the differentially expressed mRNAs between MS patients and controls resulting in 920 overlapping genes.

\section{Competing interests}

MJ, MA, IN, HW and BO do not have any competing interests in this study. $\mathrm{CM}$ has received travel grants and lecture fees from Biogenldec and Merck and compensation for advisory board participation from Novartis. JL has served on advisory boards for Biogen Idec and Merck Serono; has grants pending from Biogen Idec and Novartis; has received speakers honoraria from Biogen Idec, Merck Serono, TEVA and Novartis; and has had travel expenses reimbursed by Biogen Idec.

\section{Authors' contribution}

MJ designed and coordinated the study, performed all laboratory work, analyzed and interpreted the data and wrote the paper. IN analyzed and interpreted data and wrote the paper. CM and MA collected the patient material, interpreted the data and wrote the paper. HW and $J \mathrm{~L}$ interpreted the data and wrote the paper. BO designed and coordinated the study, analyzed and interpreted data and wrote the paper. All authors read and approved the final manuscript.

\section{Acknowledgement}

Work in the authors' laboratory is supported by grants from the Swedish Research Council (K2009-65X-15424-05-3, K2011-X-20401-05-6), The Swedish federal government under the LUA/ALF agreement, The Foundations of the National Board of Health and Welfare, Torsten and Ragnar Söderberg Foundation, Clas Groschinsky Foundation, the Arosenius Foundation, Åke Wiberg Foundation, Jeansson Foundation, Tore Nilsson Foundation for Medical Research, Magnus Bergvall Foundation, Wilhelm and Martina Lundgren Science Foundation. Chalmers Foundation, Knut and Alice Wallenberg Foundation and Bioinformatics Infrastructure for Life Sciences (BILS).

\section{Author details}

'Department of Molecular and Clinical Medicine, The Sahlgrenska Academy at University of Gothenburg, Gothenburg, Sweden. ${ }^{2}$ Department of Neurology, The Sahlgrenska Academy at University of Gothenburg, Gothenburg, Sweden. ${ }^{3}$ Department of Internal Medicine, Institute of Medicine, The Sahlgrenska Academy at University of Gothenburg, Vita Stråket 12, SE-413 45, Gothenburg, Sweden. ${ }^{4}$ Department of Psychiatry and Neurochemistry, The Sahlgrenska Academy at University of Gothenburg, Gothenburg, Sweden. ${ }^{5}$ Department of Chemical and Biological Engineering, Chalmers University of Technology, Gothenburg, Sweden.

Received: 25 February 2013 Accepted: 24 July 2013

Published: 29 July 2013

\section{References}

1. Frohman EM, Racke MK, Raine CS: Multiple sclerosis-the plaque and its pathogenesis. N Engl J Med 2006, 354:942-955.

2. Kasper LH, Shoemaker J: Multiple sclerosis immunology: the healthy immune system vs the MS immune system. Neurology 2010, 74(Suppl 1):S2-8.

3. Flynt AS, Lai EC: Biological principles of microRNA-mediated regulation: shared themes amid diversity. Nat Rev Genet 2008, 9:831-842.

4. Lewis BP, Burge CB, Bartel DP: Conserved seed pairing, often flanked by adenosines, indicates that thousands of human genes are microRNA targets. Cell 2005, 120:15-20.

5. Grimson A, Farh KK, Johnston WK, Garrett-Engele P, Lim LP, Bartel DP: MicroRNA targeting specificity in mammals: determinants beyond seed pairing. Mol Cell 2007, 27:91-105.

6. Kozomara A, Griffiths-Jones S: miRBase: integrating microRNA annotation and deep-sequencing data. Nucleic Acids Res 2011, 39:D152-157.

7. Sonkoly E, Pivarcsi A: Advances in microRNAs: implications for immunity and inflammatory diseases. J Cell Mol Med 2009, 13:24-38.

8. Iborra M, Bernuzzi F, Invernizzi P, Danese S: MicroRNAs in autoimmunity and inflammatory bowel disease: crucial regulators in immune response. Autoimmun Rev 2012, 11:305-314.

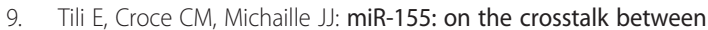
inflammation and cancer. Int Rev Immunol 2009, 28:264-284.

10. Sayed D, Abdellatif M: MicroRNAs in development and disease. Physio/ Rev 2011, 91:827-887

11. Guerau-de-Arellano M, Alder H, Ozer HG, Lovett-Racke A, Racke MK: miRNA profiling for biomarker discovery in multiple sclerosis: from microarray to deep sequencing. J Neuroimmunol 2012, 248:32-39.

12. Chen CZ, Li L, Lodish HF, Bartel DP: MicroRNAs modulate hematopoietic lineage differentiation. Science 2004, 303:83-86.

13. Baltimore D, Boldin MP, O'Connell RM, Rao DS, Taganov KD: MicroRNAs: new regulators of immune cell development and function. Nat Immunol 2008, 9:839-845.

14. O'Connell RM, Rao DS, Chaudhuri AA, Baltimore D: Physiological and pathological roles for microRNAs in the immune system. Nat Rev Immunol 2010, 10:111-122. 
15. Pedersen I, David M: MicroRNAs in the immune response. Cytokine 2008, 43:391-394.

16. Gantier MP: New perspectives in MicroRNA regulation of innate immunity. J Interferon Cytokine Res 2010, 30:283-289.

17. Liston A, Lu LF, O'Carroll D, Tarakhovsky A, Rudensky AY: Dicer-dependent microRNA pathway safeguards regulatory T cell function. J Exp Med 2008, 205:1993-2004.

18. Zhou X, Jeker LT, Fife BT, Zhu S, Anderson MS, McManus MT, Bluestone JA: Selective miRNA disruption in T reg cells leads to uncontrolled autoimmunity. J Exp Med 2008, 205:1983-1991.

19. Wu H, Neilson JR, Kumar P, Manocha M, Shankar P, Sharp PA, Manjunath N: miRNA profiling of naive, effector and memory CD8 T cells. PLOS One 2007, 2:e1020

20. Chong MM, Rasmussen JP, Rudensky AY, Littman DR: The RNAselll enzyme Drosha is critical in T cells for preventing lethal inflammatory disease. J Exp Med 2008, 205:2005-2017.

21. Turner M, Vigorito E: Regulation of B- and T-cell differentiation by a single microRNA. Biochem Soc Trans 2008, 36:531-533.

22. Curtale G, Citarella F, Carissimi C, Goldoni M, Carucci N, Fulci V, Franceschini D, Meloni F, Barnaba $V$, Macino G: An emerging player in the adaptive immune response: microRNA-146a is a modulator of IL-2 expression and activation-induced cell death in T lymphocytes. Blood 2010, 115:265-273.

23. Otaegui D, Baranzini SE, Armananzas R, Calvo B, Munoz-Culla M, Khankhanian P, Inza I, Lozano JA, Castillo-Trivino T, Asensio A, et al: Differential micro RNA expression in PBMC from multiple sclerosis patients. PLoS One 2009, 4:e6309.

24. Keller A, Leidinger $P$, Lange J, Borries A, Schroers $H$, Scheffler M, Lenhof HP Ruprecht K, Meese E: Multiple sclerosis: microRNA expression profiles accurately differentiate patients with relapsing-remitting disease from healthy controls. PLoS One 2009, 4:e7440.

25. Du C, Liu C, Kang J, Zhao G, Ye Z, Huang S, Li Z, Wu Z, Pei G: MicroRNA miR-326 regulates $\mathrm{TH}-17$ differentiation and is associated with the pathogenesis of multiple sclerosis. Nat Immunol 2009, 10:1252-1259.

26. Lindberg RL, Hoffmann F, Mehling M, Kuhle J, Kappos L: Altered expression of miR-17-5p in CD4+ lymphocytes of relapsing-remitting multiple sclerosis patients. Eur J Immunol 2010, 40:888-898.

27. Cox MB, Cairns MJ, Gandhi KS, Carroll AP, Moscovis S, Stewart GJ, Broadley S, Scott RJ, Booth DR, Lechner-Scott J: MicroRNAs miR-17 and miR-20a inhibit T cell activation genes and are under-expressed in MS whole blood. PLoS One 2010, 5:e12132.

28. Junker A, Krumbholz M, Eisele S, Mohan H, Augstein F, Bittner R, Lassmann $H$, Wekerle $H$, Hohlfeld R, Meinl E: MicroRNA profiling of multiple sclerosis lesions identifies modulators of the regulatory protein CD47. Brain 2009, 132:3342-3352.

29. De Santis G, Ferracin M, Biondani A, Caniatti L, Rosaria Tola M, Castellazzi M, Zagatti B, Battistini L, Borsellino G, Fainardi E, et al: Altered miRNA expression in T regulatory cells in course of multiple sclerosis. $J$ Neuroimmunol 2010, 226:165-171

30. Fenoglio C, Cantoni C, De Riz M, Ridolfi E, Cortini F, Serpente M, Villa C, Comi C, Monaco F, Mellesi L, et al: Expression and genetic analysis of miRNAs involved in CD4+ cell activation in patients with multiple sclerosis. Neurosci Lett 2011, 504:9-12.

31. Angerstein C, Hecker M, Paap BK, Koczan D, Thamilarasan M, Thiesen HJ, Zettl UK: Integration of MicroRNA databases to study MicroRNAs associated with multiple sclerosis. Mol Neurobiol 2012, 45:520-535.

32. Fenoglio C, Ridolfi E, Galimberti D, Scarpini E: MicroRNAs as Active Players in the Pathogenesis of Multiple Sclerosis. Int J Mol Sci 2012, 13:13227-13239.

33. Haghikia A, Hellwig K, Baraniskin A, Holzmann A, Decard BF, Thum T, Gold R: Regulated microRNAs in the CSF of patients with multiple sclerosis: a case-control study. Neurology 2012, 79:2166-2170

34. Siegel SR, Mackenzie J, Chaplin G, Jablonski NG, Griffiths L: Circulating microRNAs involved in multiple sclerosis. Mol Biol Rep 2012 39:6219-6225

35. Malmestrom C, Lycke J, Haghighi S, Andersen O, Carlsson L, Wadenvik H, Olsson B: Relapses in multiple sclerosis are associated with increased CD8+ T-cell mediated cytotoxicity in CSF. J Neuroimmunol 2008, 196:159-165.

36. McDonald WI, Compston A, Edan G, Goodkin D, Hartung HP, Lublin FD, McFarland HF, Paty DW, Polman CH, Reingold SC, et al: Recommended diagnostic criteria for multiple sclerosis: guidelines from the International Panel on the diagnosis of multiple sclerosis. Ann Neurol 2001, 50:121-127.
37. Polman $\mathrm{CH}$, Wolinsky JS, Reingold SC: Multiple sclerosis diagnostic criteria: three years later. Mult Scler 2005, 11:5-12

38. Kurtzke JF: Rating neurologic impairment in multiple sclerosis: an expanded disability status scale (EDSS). Neurology 1983, 33:1444-1452.

39. Olsson B, Andersson PO, Jernas M, Jacobsson S, Carlsson B, Carlsson LM, Wadenvik H: T-cell-mediated cytotoxicity toward platelets in chronic idiopathic thrombocytopenic purpura. Nat Med 2003, 9:1123-1124.

40. Chomczynski P, Sacchi N: Single-step method of RNA isolation by acid guanidinium thiocyanate-phenol-chloroform extraction. Anal Biochem 1987, 162:156-159.

41. Brazma A, Hingamp P, Quackenbush J, Sherlock G, Spellman P, Stoeckert C, Aach J, Ansorge W, Ball CA, Causton HC, et al: Minimum information about a microarray experiment (MIAME)-toward standards for microarray data. Nat Genet 2001, 29:365-371.

42. Therneau TM, Ballman KV: What Does PLIER Really Do? Cancer Inform 2008, 6:423-431.

43. Smyth GK: Linear models and empirical bayes methods for assessing differential expression in microarray experiments. Stat App/ Genet Mol Biol 2004, 3:Article3.

44. Benjamini Y, Drai D, Elmer G, Kafkafi N, Golani I: Controlling the false discovery rate in behavior genetics research. Behav Brain Res 2001, 125:279-284.

45. Oliveira AP, Patil KR, Nielsen J: Architecture of transcriptional regulatory circuits is knitted over the topology of bio-molecular interaction networks. BMC Syst Biol 2008, 2:17.

46. Patil KR, Nielsen J: Uncovering transcriptional regulation of metabolism by using metabolic network topology. Proc Natl Acad Sci U S A 2005, 102:2685-2689.

47. Väremo L, Nielsen J, Nookaew I: Enriching the gene set analysis of genome-wide data by incorporating directionality of gene expression and combining statistical hypotheses and methods. Nucleic Acids Res 2013, 41:4378-4391.

48. John B, Sander C, Marks DS: Prediction of human microRNA targets. Methods Mol Biol 2006, 342:101-113.

49. Friedman RC, Farh KK, Burge CB, Bartel DP: Most mammalian mRNAs are conserved targets of microRNAs. Genome Res 2009, 19:92-105.

50. Betel D, Wilson M, Gabow A, Marks DS, Sander C: The microRNA.org resource: targets and expression. Nucleic Acids Res 2008, 36:D149-153.

51. Bartel DP: MicroRNAs: target recognition and regulatory functions. Cell 2009, 136:215-233

52. Livak KJ, Schmittgen TD: Analysis of relative gene expression data using real-time quantitative PCR and the 2(-Delta Delta C(T)) Method. Methods 2001, 25:402-408

53. Diehl AD, Lee JA, Scheuermann RH, Blake JA: Ontology development for biological systems: immunology. Bioinformatics 2007, 23:913-915.

54. Bindea G, Mlecnik B, Hackl H, Charoentong P, Tosolini M, Kirilovsky A, Fridman WH, Pages F, Trajanoski Z, Galon J: ClueGO: a Cytoscape plug-in to decipher functionally grouped gene ontology and pathway annotation networks. Bioinformatics 2009, 25:1091-1093.

55. Martinelli-Boneschi F, Fenoglio C, Brambilla P, Sorosina M, Giacalone G, Esposito F, Serpente M, Cantoni C, Ridolfi E, Rodegher M, et al: MicroRNA and mRNA expression profile screening in multiple sclerosis patients to unravel novel pathogenic steps and identify potential biomarkers. Neurosci Lett 2012, 508:4-8.

56. Anderson DC, Rothlein R, Marlin SD, Krater SS, Smith CW: Impaired transendothelial migration by neonatal neutrophils: abnormalities of Mac-1 (CD11b/CD18)-dependent adherence reactions. Blood 1990, 76:2613-2621.

57. Bullard DC, Hu X, Schoeb TR, Axtell RC, Raman C, Barnum SR: Critical requirement of CD11b (Mac-1) on T cells and accessory cells for development of experimental autoimmune encephalomyelitis. $J$ Immunol 2005, 175:6327-6333.

58. Zang YC, Samanta AK, Halder JB, Hong J, Tejada-Simon MV, Rivera VM, Zhang JZ: Aberrant T cell migration toward RANTES and MIP-1 alpha in patients with multiple sclerosis. Overexpression of chemokine receptor CCR5. Brain 2000, 123(Pt 9):1874-1882.

59. Dos Santos AC, Barsante MM, Arantes RM, Bernard CC, Teixeira MM Carvalho-Tavares J: CCL2 and CCL5 mediate leukocyte adhesion in experimental autoimmune encephalomyelitis-an intravital microscopy study. J Neuroimmunol 2005, 162:122-129.

60. Eltayeb S, Sunnemark D, Berg AL, Nordvall G, Malmberg A, Lassmann H, Wallstrom E, Olsson T, Ericsson-Dahlstrand A: Effector stage CC chemokine 
receptor-1 selective antagonism reduces multiple sclerosis-like rat disease. J Neuroimmunol 2003, 142:75-85.

61. Karpus WJ, Lukacs NW, McRae BL, Strieter RM, Kunkel SL, Miller SD: An important role for the chemokine macrophage inflammatory protein-1 alpha in the pathogenesis of the T cell-mediated autoimmune disease, experimental autoimmune encephalomyelitis. J Immunol 1995, 155:5003-5010.

62. Racke MK, Dhib-Jalbut S, Cannella B, Albert PS, Raine CS, McFarlin DE: Prevention and treatment of chronic relapsing experimental allergic encephalomyelitis by transforming growth factor-beta 1. J Immunol 1991, 146:3012-3017.

63. Kulkarni $A B$, Huh CG, Becker D, Geiser A, Lyght M, Flanders KC, Roberts AB, Sporn MB, Ward JM, Karlsson S: Transforming growth factor beta 1 null mutation in mice causes excessive inflammatory response and early death. Proc Natl Acad Sci U S A 1993, 90:770-774.

64. Soroosh P, Doherty TA, So T, Mehta AK, Khorram N, Norris PS, Scheu S, Pfeffer K, Ware C, Croft M: Herpesvirus entry mediator (TNFRSF14) regulates the persistence of T helper memory cell populations. J Exp Med 2011, 208:797-809.

65. Tamada K, Shimozaki K, Chapoval Al, Zhu G, Sica G, Flies D, Boone T, Hsu H, Fu YX, Nagata S, et al: Modulation of T-cell-mediated immunity in tumor and graft-versus-host disease models through the LIGHT co-stimulatory pathway. Nat Med 2000, 6:283-289.

66. Shaikh RB, Santee S, Granger SW, Butrovich K, Cheung T, Kronenberg M, Cheroutre H, Ware CF: Constitutive expression of LIGHT on T cells leads to lymphocyte activation, inflammation, and tissue destruction. J Immunol 2001, 167:6330-6337.

67. Wang J, Anders RA, Wang Y, Turner JR, Abraham C, Pfeffer K, Fu YX: The critical role of LIGHT in promoting intestinal inflammation and Crohn's disease. J Immunol 2005, 174:8173-8182.

68. Wang J, Lo JC, Foster A, Yu P, Chen HM, Wang Y, Tamada K, Chen L, Fu YX: The regulation of $\mathrm{T}$ cell homeostasis and autoimmunity by $\mathrm{T}$ cell-derived LIGHT. J Clin Invest 2001, 108:1771-1780.

69. Doherty TA, Soroosh P, Khorram N, Fukuyama S, Rosenthal P, Cho JY, Norris PS, Choi H, Scheu S, Pfeffer K, et al: The tumor necrosis factor family member LIGHT is a target for asthmatic airway remodeling. Nat Med 2011, 17:596-603.

70. Yu P, Lee Y, Liu W, Chin RK, Wang J, Wang Y, Schietinger A, Philip M, Schreiber H, Fu YX: Priming of naive T cells inside tumors leads to eradication of established tumors. Nat Immunol 2004, 5:141-149.

71. Cheung TC, Humphreys IR, Potter KG, Norris PS, Shumway HM, Tran BR, Patterson G, Jean-Jacques R, Yoon M, Spear PG, et al: Evolutionarily divergent herpesviruses modulate $T$ cell activation by targeting the herpesvirus entry mediator cosignaling pathway. Proc Natl Acad Sci U S A 2005, 102:13218-13223.

72. Cheung TC, Oborne LM, Steinberg MW, Macauley MG, Fukuyama S, Sanjo H, D'Souza C, Norris PS, Pfeffer K, Murphy KM, et al: T cell intrinsic heterodimeric complexes between HVEM and BTLA determine receptivity to the surrounding microenvironment. J Immunol 2009, 183:7286-7296.

73. Cheung TC, Steinberg MW, Oborne LM, Macauley MG, Fukuyama S, Sanjo H, D'Souza C, Norris PS, Pfeffer K, Murphy KM, et al: Unconventional ligand activation of herpesvirus entry mediator signals cell survival. Proc Nat Acad Sci U S A 2009, 106:6244-6249.

74. Shui JW, Steinberg MW, Kronenberg M: Regulation of inflammation, autoimmunity, and infection immunity by HVEM-BTLA signaling. J Leukoc Biol 2011, 89:517-523.

doi:10.1186/1471-2172-14-32

Cite this article as: Jernås et al: MicroRNA regulate immune pathways in T-cells in multiple sclerosis (MS). BMC Immunology 2013 14:32.

\section{Submit your next manuscript to BioMed Central and take full advantage of:}

- Convenient online submission

- Thorough peer review

- No space constraints or color figure charges

- Immediate publication on acceptance

- Inclusion in PubMed, CAS, Scopus and Google Scholar

- Research which is freely available for redistribution

Submit your manuscript at www.biomedcentral.com/submit 